\title{
Densities, Viscosities, and Surface and Interfacial Tensions of the Ternary Mixture Water + Ethyl Butyrate + Methanol at 303.15 K
}

\author{
Mirjana Lj. Kijevcanin, Inês S. A. Ribeiro, Abel G. M. Ferreira, and Isabel M. A. Fonseca* \\ Department of Chemical Engineering, University of Coimbra, Pólo II-Pinhal de Marrocos, \\ 3030-290 Coimbra, Portugal, and Faculty of Technology and Metallurgy, University of Belgrade, Karnegijeva 4, \\ 11000 Belgrade, Yugoslavia
}

\begin{abstract}
The excess molar volumes, $\mathrm{VE}$, viscosity deviations, $\Delta \eta$, and excess surface tensions were calculated from the measured density, viscosity, and surface tension values, $\sigma$, over the whole miscibility composition range for the ternary system water + ethyl butyrate + methanol and their constituent binaries, at 303.15 $\mathrm{K}$ and atmospheric pressure. The liquid interfacial tension was measured in the liquid-liquid equilibrium range at the same conditions of temperature and pressure. A Redlich-Kister type equation was used to correlate binary and ternary $\mathrm{VE}$ and $\Delta \eta$ data. For the correlation of the surface tension of binary and ternary data, the Santos et al. equation was used. The interfacial tension was correlated with the Li and Fu equation.
\end{abstract}

\section{Introduction}

Thermodynamic and transport properties are fundamental in the design of process units that involve fluid flow, interface heat, and mass transfer. In the past few years we have been developed a research program that consists of the experimental determination of densities, viscosities, and surface and interfacial tensions of binary and ternary mixtures. ${ }^{1-4}$

In the present work we have measured densities, viscosities, and surface and interfacial tensions for the ternary system water + ethyl butyrate + methanol, at $303.15 \mathrm{~K}$ and atmospheric pressure. The related properties excess molar volume, viscosity deviation, and excess surface tension were derived from the measured data. This ternary system shows liquid-liquid immiscibility in a wide composition range. The compositions of the liquid phases in equilibrium were measured by Rao and Rao. ${ }^{5}$

The excess molar volume, VE, and viscosity deviations, $\Delta \eta$, are often used to study qualitatively the intermolecular forces in mixtures, helping us to understand their real behavior and develop models for its description. On the other hand, the surface tension, $\sigma$, and the interfacial tension, $\sigma^{\prime}$, of liquid mixtures are essential properties in process design, but the available experimental data are relatively scarce. ${ }^{6}$

The $\mathrm{VE}$ and $\Delta \eta$ of binary and ternary data were correlated using Redlich-Kister type equations. However, the correlation of the binary surface tension data has been made using the Santos et al. ${ }^{4}$ expression, since the best results are obtained using this simple equation, as was shown in our previous paper. ${ }^{4}$ The liquid interfacial tension was correlated using the equation of $\mathrm{Li}$ and $\mathrm{Fu}{ }^{7}$

\section{Experimental Section}

Materials. The pure water (water G Chromasolv) was supplied by Riedel de Häen. Methanol (Panreac) was supplied with a purity > 99.8 mass \%, while the ethyl butyrate (Riedel de Häen and Acros) was supplied with a

\footnotetext{
* To whom correspondence should be addressed. Telephone: +351-
} 239798728. Fax: +351-239798703. E-mail: fonseca@eq.uc.pt.
Table 1. Densities, $\rho$, Viscosities, $\eta$, and Surface Tensions, $\sigma$, of the Pure Components at 303.15 K and Atmospheric Pressure

\begin{tabular}{|c|c|c|c|c|c|c|}
\hline \multirow[b]{2}{*}{ component } & \multicolumn{2}{|c|}{$\rho / \mathrm{g} \cdot \mathrm{cm}^{-3}$} & \multicolumn{2}{|c|}{$\eta / \mathrm{mPa} \cdot \mathrm{s}$} & \multicolumn{2}{|c|}{$\sigma / \mathrm{mN} \cdot \mathrm{m}^{-1}$} \\
\hline & exptl & lit. & exptl & lit. & exptl & lit. \\
\hline water & & $0.99570^{8}$ & & 0.79713 & & $71.40^{4,6}$ \\
\hline ethyl b & 0.86821 & $\begin{array}{l}0.86850^{9} \\
0.8688310\end{array}$ & 0.591 & $0.577^{14}$ & 23.40 & $23.41^{17}$ \\
\hline methanol & 0.78191 & $\begin{array}{l}0.78196^{11} \\
0.78182^{12} \\
0.78200^{9} \\
0.78199^{2}\end{array}$ & 0.504 & $\begin{array}{l}0.510^{15} \\
0.503^{16} \\
0.516^{2}\end{array}$ & 21.68 & $21.71^{6}$ \\
\hline
\end{tabular}

purity $>99 \%$. Table 1 lists the measured densities, viscosities, and surface tensions of ethyl butyrate and methanol together with the values found in the literature. Since the agreement is very good, all the compounds were used without further purification. Mixtures were prepared by mass using a Mettler AT 200 balance with an uncertainty of $\pm 10^{-5} \mathrm{~g}$. The uncertainty of the mole fraction compositions of the mixtures for which we have determined the densities and viscosities is estimated to be of the order $\pm 10^{-4}$. For the mixtures for which surface and interfacial tensions were measured, the uncertainty of the mole fraction compositions is $\pm 10^{-3}$, since these measurements took place in an open vessel. This value was obtained by weighing the prepared binary solutions at the beginning and at the end of the experiences, which allows us to determine the evaporated mass of liquid.

Measurements. Densities were measured in an Anton Paar DMA 60 digital vibrating tube densimeter, with a DMA 602 measuring cell. Air and pure water were used for the calibration of the densimeter. Viscosities were obtained with a Haake falling ball viscosimeter (Hoppler design), calibrated with pure water. An electronic digital stopwatch, with an uncertainty of $\pm 0.01 \mathrm{~s}$, was used to measure the falling time of the ball. In all the measurements, the temperature maintenance and control were performed using a Haake D8-G thermostatic water bath, which has a temperature uncertainty of $\pm 0.01 \mathrm{~K}$. In the case of density measurements, the Pt resistance thermometer (calibrated against a precision mercury thermometer, graduated in $0.01 \mathrm{~K}$, certified by NPL, U.K.) was placed 
Table 2. Densities, $\rho$, and Excess Molar Volumes, VE, for the System Water (1) + Ethyl Butyrate (2) + Methanol (3) and Its Binary Constituents, at 303.15 K and Atmospheric Pressure

\begin{tabular}{|c|c|c|c|c|c|c|c|}
\hline $\mathrm{x}_{1}$ & $x_{2}$ & $\frac{\rho}{\mathrm{g} \cdot \mathrm{cm}^{-3}}$ & $\frac{\mathrm{VE}}{\mathrm{cm}^{3} \cdot \mathrm{mol}^{-1}}$ & $\mathrm{X}_{1}$ & $x_{2}$ & $\frac{\rho}{\mathrm{g} \cdot \mathrm{cm}^{-3}}$ & $\frac{\mathrm{VE}}{\mathrm{cm}^{3} \cdot \mathrm{mol}^{-1}}$ \\
\hline 0 & 0.1993 & 0.82083 & -0.017 & 0.1061 & 0.3576 & 0.84861 & -0.289 \\
\hline 0 & 0.3000 & 0.83261 & -0.030 & 0.1111 & 0.4408 & 0.85443 & -0.275 \\
\hline 0 & 0.4000 & 0.84145 & -0.037 & 0.1207 & 0.6186 & 0.86316 & -0.186 \\
\hline 0 & 0.4995 & 0.84830 & -0.037 & 0.1317 & 0.3093 & 0.84766 & -0.357 \\
\hline 0 & 0.5997 & 0.85394 & -0.042 & 0.1434 & 0.5910 & 0.86421 & -0.275 \\
\hline 0 & 0.9001 & 0.86554 & -0.025 & 0.1537 & 0.2483 & 0.84507 & -0.426 \\
\hline 0 & 0.4490 & 0.84503 & -0.038 & 0.1572 & 0.3371 & 0.85241 & -0.400 \\
\hline 0 & 0.4740 & 0.84671 & -0.039 & 0.1586 & 0.1677 & 0.83746 & -0.465 \\
\hline 0 & 0.6500 & 0.85633 & -0.040 & 0.1705 & 0.4976 & 0.86137 & -0.245 \\
\hline 0 & 0.7495 & 0.86043 & -0.030 & 0.1850 & 0.0994 & 0.83229 & -0.544 \\
\hline 0 & 0.8990 & 0.86548 & -0.019 & 0.1952 & 0.0499 & 0.82627 & -0.598 \\
\hline 0 & 0.9465 & 0.86688 & -0.020 & 0.2023 & 0.3191 & 0.85616 & -0.503 \\
\hline 0.0560 & 0.9440 & 0.86898 & 0.036 & 0.2055 & 0.0000 & 0.81852 & -0.651 \\
\hline 0.0390 & 0.9610 & 0.86871 & 0.029 & 0.2099 & 0.1575 & 0.84339 & -0.584 \\
\hline 0.0330 & 0.9670 & 0.86846 & 0.050 & 0.2250 & 0.3389 & 0.86017 & -0.561 \\
\hline 0.0190 & 0.9810 & 0.86819 & 0.054 & 0.2503 & 0.2999 & 0.86014 & -0.586 \\
\hline 0.0471 & 0.3999 & 0.84612 & -0.172 & 0.2561 & 0.1504 & 0.84889 & -0.660 \\
\hline 0.0507 & 0.7903 & 0.86511 & -0.109 & 0.2709 & 0.1012 & 0.84568 & -0.710 \\
\hline 0.0514 & 0.4738 & 0.85121 & -0.160 & 0.2866 & 0.0491 & 0.84171 & -0.779 \\
\hline 0.0521 & 0.1889 & 0.82626 & -0.193 & 0.3014 & 0.0000 & 0.83697 & -0.849 \\
\hline 0.0523 & 0.0962 & 0.81192 & -0.183 & 0.3021 & 0.2473 & 0.86237 & -0.654 \\
\hline 0.0531 & 0.5679 & 0.85649 & -0.156 & 0.3218 & 0.1982 & 0.86155 & -0.707 \\
\hline 0.0563 & 0.6639 & 0.86099 & -0.149 & 0.3415 & 0.1490 & 0.85974 & -0.717 \\
\hline 0.0847 & 0.7201 & 0.86502 & -0.181 & 0.3516 & 0.1995 & 0.86513 & -0.714 \\
\hline 0.0900 & 0.2763 & 0.84010 & -0.260 & 0.3613 & 0.0997 & 0.85974 & -0.835 \\
\hline 0.0980 & 0.0499 & 0.81007 & -0.328 & 0.3813 & 0.0500 & 0.85853 & -0.902 \\
\hline 0.1030 & 0.0911 & 0.81881 & -0.351 & 0.4013 & 0.0000 & 0.85706 & -0.977 \\
\hline 0.1031 & 0.0000 & 0.79974 & -0.362 & 0.4495 & 0.0997 & 0.87358 & -0.884 \\
\hline 0.1032 & 0.4705 & 0.85513 & -0.226 & 0.4744 & 0.0500 & 0.87534 & -0.955 \\
\hline 0.1032 & 0.5378 & 0.85855 & -0.205 & 0.4994 & 0.0000 & 0.87748 & -1.017 \\
\hline 0.1034 & 0.1787 & 0.83137 & -0.321 & & & & \\
\hline
\end{tabular}

inside the vibrating tube densimeter to find the actual temperature of the measurements. The temperature was maintained at $(303.15 \pm 0.01) \mathrm{K}$.

Surface and interfacial tensions were measured using a PC controlled KSV Sigma 70 tension balance which employs the Du Noüy ring-detachment method. The platinum ring was thoroughly cleaned by immersion in a concentrated solution of nitric acid during several hours. Then it was rinsed with distilled water and flame dried before each measurement. The measurements were automatically corrected by means of the Huh and Mason compensation for interface distortion. The temperature inside the surface tension measurement vessel was maintained and controlled at $(303.15 \pm 0.10) \mathrm{K}$ using a J ulabo FP50 bath.

For the liquid interfacial tension measurements, the mixture with a known global composition was kept at $303.15 \mathrm{~K}$ in a thermostated vessel and shaken several times during a period of at least $24 \mathrm{~h}$ to reach the equilibrium. The surface tension of each liquid phase was also measured separately.

Uncertainties. Densities were measured with an uncertainty of $\pm 10^{-5} \mathrm{~g} \cdot \mathrm{cm}^{-3}$. Having in mind that the error in the excess molar volume, $\mathrm{VE}$, is determined by the uncertainties in mole fraction and density, the maximum error in $\mathrm{VE}$ resulting from the propagation of errors is $5 \times$ $10^{-3} \mathrm{~cm}^{3} \cdot \mathrm{mol}^{-1}$. Taking into account the uncertainties in the measured time and in the density, the experimental uncertainty in the viscosity is $\pm 0.001 \mathrm{mPa} \cdot$ s. The uncertainty of the surface and interfacial tensions is indicated by the instruction manual of the tension balance to be of the order of $\pm 0.01 \mathrm{mN} \cdot \mathrm{m}^{-1}$.

\section{Results and Discussion}

The excess molar volumes, VE, were calculated from the densities by the equation

$$
\mathrm{V}^{\mathrm{E}}=\rho^{-1}\left(\sum \mathrm{x}_{\mathrm{i}} \mathrm{M}_{\mathrm{i}}\right)-\sum \mathrm{x}_{\mathrm{i}} \mathrm{M}_{\mathrm{i}} \rho_{\mathrm{i}}^{-1}
$$

where $x_{i}$ is the mole fraction of component $i$ in the mixture, $\mathrm{M}_{\mathrm{i}}$ is its molecular weight, and $\rho$ and $\rho_{\mathrm{i}}$ are the measured densities of the mixture and the pure component, respectively.

The calculation of the dynamic viscosity is done according to the formula

$$
\eta=\mathrm{K}\left(\rho_{\mathrm{b}}-\rho\right) \mathrm{t}
$$

where $t$ is the falling time of the ball measured with the stopwatch. $\mathrm{K}$ is a calibration constant, and $\rho_{\mathrm{b}}$ and $\rho$ represent the densities of the ball and the liquid, respectively. $\rho$ was calculated through eq 1 . The $V^{E}$ values are obtained by eqs 5 and 7 for binary and ternary systems, respectively.

The viscosity deviations, $\Delta \eta$, were obtained using the expression

$$
\Delta \eta=\eta-\sum x_{\mathrm{i}} \eta_{\mathrm{i}}
$$

where $\eta$ is the measured mixture viscosity and $\eta_{\mathrm{i}}$ represents the pure component viscosity.

The composition dependence of the surface tensions of mixtures can be represented in terms of the excess surface tension, $\sigma^{\mathrm{E}}$, defined as

$$
\sigma^{\mathrm{E}}=\sigma-\sum \mathrm{x}_{\mathrm{i}} \sigma_{\mathrm{i}}
$$

where $\sigma$ is the surface tension of the mixture and $\sigma_{\mathrm{i}}$ is the surface tension of the ith component of mole fraction $x_{i}$.

Table 2 lists the measured densities, $\rho$, and the corresponding values of $\mathrm{VE}$, Table 3 presents the measured viscosities, $\eta$, and the corresponding $\Delta \eta$ values, and the measured surface tensions and the corresponding excess surface tensions as a function of the composition are shown in Table 4, for the ternary system and its constituent binary systems. Experimental results for the binary water (1) + 
1268 J ournal of Chemical and Engineering Data, Vol. 48, No. 5, 2003

Table 3. Viscosities, $\eta$, and Viscosity Deviations, $\Delta \eta$, for the System Water (1) + Ethyl Butyrate (2) + Methanol (3) and Its Binary Constituents, at $303.15 \mathrm{~K}$ and Atmospheric Pressure

\begin{tabular}{|c|c|c|c|c|c|c|c|}
\hline & & $\eta$ & $\Delta \eta$ & & & $\eta$ & $\Delta \eta$ \\
\hline$x_{1}$ & $x_{2}$ & $\overline{\mathrm{mPa} \cdot \mathrm{s}}$ & $\overline{\mathrm{mPa} \cdot \mathrm{s}}$ & $x_{1}$ & $x_{2}$ & $\overline{\mathrm{mPa} \cdot \mathrm{s}}$ & $\overline{\mathrm{mPa}}$ \\
\hline 0 & 0.9004 & .577 & -0.005 & 0.1205 & 0.1369 & 0.633 & 0.0 \\
\hline 0 & & & -0 & & & & \\
\hline 0 & & 5 & -0.014 & 0.1415 & & 0.050 & \\
\hline 0 & 6 & 543 & -0.015 & & & & \\
\hline 0 & 064 & 0.5 & -0.013 & 0.1 & & 0.6 & \\
\hline 0 & & & & & & & \\
\hline 0 & & 0 & -0 . & & & & \\
\hline 0 & & & -0. & & & & 00 \\
\hline 0 & & 1 & -0 . & & & & \\
\hline & & & -0. & & & & \\
\hline & & & & & & & \\
\hline & & & -0 . & & & 3 & \\
\hline & & & & & & & \\
\hline & 0.9 & 0.597 & -0 . & 0.2 & & 0.740 & \\
\hline & & & & & & & \\
\hline & 0.7 & 0 & -0. & 0.3 & & 0.8 & \\
\hline & & & & & & & \\
\hline & & & & & & $0 . \varepsilon$ & \\
\hline & & 0. & 0. & & & & \\
\hline 0.09 & 0. & 0 & & 0.4 & & & \\
\hline 0.095 & 0.6997 & 0.585 & -0.008 & 0.4597 & 0.0640 & 1.120 & \\
\hline
\end{tabular}

Table 4. Surface Tension, $\sigma$, and Excess Surface Tension, $\sigma^{\mathrm{E}}$, for the System Water (1) + Ethyl Butyrate (2) + Methanol (3) and Its Binary Constituents, at $303.15 \mathrm{~K}$ and Atmospheric Pressure

\begin{tabular}{lcccccccr}
\hline & & $\sigma$ & $\sigma^{\mathrm{E}}$ & & & $\sigma$ & \\
$\mathrm{x}_{1}$ & $\mathrm{x}_{2}$ & $\mathrm{mN} \cdot \mathrm{m}^{-1}$ & $\mathrm{mN} \cdot \mathrm{m}^{-1}$ & $\mathrm{x}_{1}$ & $\mathrm{x}_{2}$ & $\mathrm{mN} \cdot \mathrm{m}^{-1}$ & $\mathrm{mN} \cdot \mathrm{m}^{-1}$ \\
\hline 0 & 0.050 & 21.86 & 0.09 & 0.021 & 0.837 & 23.56 & -0.60 \\
0 & 0.101 & 22.03 & 0.18 & 0.190 & 0.050 & 24.08 & -7.13 \\
0 & 0.150 & 22.22 & 0.28 & 0.170 & 0.149 & 23.86 & -6.53 \\
0 & 0.200 & 22.36 & 0.34 & 0.149 & 0.250 & 23.78 & -5.74 \\
0 & 0.299 & 22.65 & 0.46 & 0.131 & 0.350 & 23.76 & -5.04 \\
0 & 0.400 & 22.85 & 0.48 & 0.111 & 0.450 & 23.74 & -4.23 \\
0 & 0.496 & 22.99 & 0.46 & 0.091 & 0.550 & 23.62 & -3.53 \\
0 & 0.605 & 23.12 & 0.40 & 0.070 & 0.646 & 23.50 & -2.77 \\
0 & 0.700 & 23.18 & 0.30 & 0.053 & 0.747 & 23.56 & -2.05 \\
0 & 0.800 & 23.29 & 0.23 & 0.279 & 0.050 & 25.10 & -10.54 \\
0 & 0.883 & 23.35 & 0.15 & 0.250 & 0.150 & 24.39 & -9.98 \\
0.055 & 0.945 & 23.60 & -2.44 & 0.220 & 0.249 & 23.83 & -9.22 \\
0.041 & 0.959 & 23.53 & -1.84 & 0.192 & 0.350 & 23.73 & -8.10 \\
0.018 & 0.982 & 23.46 & -0.80 & 0.161 & 0.450 & 23.64 & -6.82 \\
0.101 & 0.050 & 23.08 & -3.71 & 0.130 & 0.550 & 23.61 & -5.48 \\
0.090 & 0.150 & 23.18 & -3.23 & 0.101 & 0.650 & 23.34 & -4.48 \\
0.077 & 0.250 & 23.05 & -2.89 & 0.380 & 0.050 & 25.36 & -15.30 \\
0.069 & 0.345 & 23.19 & -2.51 & 0.341 & 0.150 & 24.04 & -14.85 \\
0.059 & 0.453 & 23.34 & -2.05 & 0.301 & 0.249 & 23.50 & -13.57 \\
0.051 & 0.549 & 23.42 & -1.74 & 0.480 & 0.050 & 25.58 & -20.05 \\
0.037 & 0.675 & 23.48 & -1.20 & 0.450 & 0.100 & 24.48 & -19.75 \\
0.033 & 0.745 & 23.58 & -1.02 & & & &
\end{tabular}

methanol (3) system are presented in previous papers..$^{2-4}$ All types of measurements were made for different compositions, since they were not performed simultaneously.

The experimental liquid interfacial tension and the values of the surface tensions of the aqueous and organic phases of the system water + ethyl butyrate + methanol are listed in Table 5.

The $\mathrm{VE}^{\mathrm{E}}$ and $\Delta \eta$ binary data were correlated using a Redlich-Kister type equation for the binary systems: ${ }^{18}$

$$
Y_{i j}=x_{i} x_{j} \sum A_{k}\left(x_{i}-x_{j}\right)^{k} \quad k=0,1,2, \ldots, n
$$

where $\mathrm{Y}_{\mathrm{ij}}$ represents $\mathrm{VE}$ and $\Delta \eta$.

For the correlation of surface tensions of binary systems, a simple equation, proposed by Santos et al., ${ }^{4}$ was used to describe the behavior of the observed systems:

$$
\frac{\sigma^{\mathrm{E}}}{\mathrm{x}_{\mathrm{i}} \mathrm{x}_{\mathrm{j}}}=\mathrm{A}+\mathrm{B}\left[1-\left(\mathrm{x}_{\mathrm{i}}-\mathrm{x}_{\mathrm{j}}\right)\right]^{\mathrm{C}}
$$

where A, B, and C are adjustable parameters.

Equation 6 correlates well the surface tensions of these systems even for the system water + methanol, which is highly nonsymmetrical with large values of $\sigma^{\mathrm{E}} .^{4}$

In Figures 1-3 we have plotted the experimental $\mathrm{V}^{\mathrm{E}}, \Delta \eta$, and $\sigma^{\mathrm{E}}$, respectively, for the binary system ethyl butyrate (2) + methanol (3) as a function of composition of the ester. As can be seen, the agreements between experimental and correlated values are reasonable, although the $\mathrm{VE}$ and $\Delta \eta$ values show some dispersion which is a consequence of the small absolute values of these properties.

The ternary data ( $\mathrm{VE}^{\mathrm{E}}$ and $\Delta \eta$ ) were correlated by a Redlich-Kister type equation: ${ }^{18}$

$$
\begin{array}{r}
Y_{123}=Y_{12}+Y_{13}+Y_{23}+x_{1} x_{2} x_{3}\left[A_{1}+B_{1}\left(x_{1}-x_{2}\right)+\right. \\
\left.B_{2}\left(x_{2}-x_{3}\right)\right]
\end{array}
$$

where $\mathrm{Y}_{123}$ represents $\mathrm{V}_{123}^{\mathrm{E}}$ and $\Delta \eta_{123}$, the excess molar volume and the viscosity deviation data for the ternary system, and $Y_{i j}$ are the values of the Redlich-Kister polynomial for the same properties of the binary systems, obtained by fitting eq 5 .

The excess surface tension for the ternary mixtures, $\sigma_{123}^{\mathrm{E}}$, has been fitted to the equation

$$
\sigma_{123}^{\mathrm{E}}=\sigma_{12}^{\mathrm{E}}+\sigma_{13}^{\mathrm{E}}+\sigma_{23}^{\mathrm{E}}+\sigma_{\mathrm{T}}^{\mathrm{E}}
$$

where the ternary term, $\sigma_{T}^{\mathrm{E}}$, is given by

$$
\sigma_{\mathrm{T}}^{\mathrm{E}}=\mathrm{x}_{1} \mathrm{x}_{2} \mathrm{x}_{3} \frac{\mathrm{D}_{1}+\mathrm{D}_{2}\left(\mathrm{x}_{1}-\mathrm{x}_{2}\right)+\mathrm{D}_{3}\left(\mathrm{x}_{2}-\mathrm{x}_{3}\right)}{1+\mathrm{D}_{4}\left(\mathrm{x}_{1}-\mathrm{x}_{2}\right)}
$$

and $\sigma_{\mathrm{ij}}^{\mathrm{E}}$ represents the excess surface tension for the binaries, which is given by eq 6 .

The Li and Fu expression ${ }^{7}$

$$
\sigma^{\prime}=\sigma_{0}^{\prime}\left(\frac{\mathrm{X}}{\mathrm{X}_{0}}\right)^{\mathrm{k}}
$$

where

\begin{tabular}{|c|c|c|c|c|c|c|c|c|}
\hline \multicolumn{2}{|c|}{ overall composition } & \multicolumn{3}{|c|}{ water layer } & \multicolumn{3}{|c|}{ organic layer } & \multirow[b]{2}{*}{$\sigma^{\prime} / \mathrm{mN} \cdot \mathrm{m}^{-1}$} \\
\hline$x_{1}$ & $x_{3}$ & $\mathrm{x}_{1}$ & $x_{3}$ & $\sigma / \mathrm{mN} \cdot \mathrm{m}^{-1}$ & $x_{1}$ & $x_{3}$ & $\sigma / \mathrm{mN} \cdot \mathrm{m}^{-1}$ & \\
\hline 0.850 & 0 & 0.999 & 0 & & 0.067 & 0 & & 15.3 \\
\hline 0.813 & 0.043 & 0.955 & 0.044 & 50.43 & 0.076 & 0.039 & 23.63 & 12.2 \\
\hline 0.754 & 0.112 & 0.892 & 0.107 & 45.29 & 0.101 & 0.123 & 23.58 & 8.4 \\
\hline 0.691 & 0.186 & 0.819 & 0.177 & 38.85 & 0.124 & 0.215 & 23.77 & 5.9 \\
\hline 0.613 & 0.279 & 0.722 & 0.269 & 28.87 & 0.185 & 0.319 & 23.80 & 2.7 \\
\hline
\end{tabular}

$$
X=-\ln \left(x_{1}^{\alpha}+x_{2}^{\beta}+x_{3 p}\right)
$$

was fitted to the interfacial tension $\sigma^{\prime}$ between the two immiscible liquid phases $\alpha$ and $\beta$ in the ternary system. $\sigma_{0}^{\prime}$

Table 5. Experimental Liquid Interfacial Tension, $\sigma^{\prime}$, for the System Water (1) + Ethyl Butyrate (2) + Methanol (3), at 303.15 K and Atmospheric Pressure ${ }^{a}$

a The surface tension, $\sigma$, and the compositions of the liquid phases at equilibrium are also indicated. 
Table 6. Coefficients of Eqs 5 and 6 Fitted to the Excess Molar Volume, VE, the Viscosity Deviation, $\Delta \eta$, and the Excess Surface Tension, $\sigma^{\mathrm{E}}$, Respectively ${ }^{\mathrm{a}}$

\begin{tabular}{|c|c|c|c|c|c|}
\hline system & property & $A_{0}$ & $A_{1}$ & $A_{2}$ & $\mathrm{~S}$ \\
\hline $\begin{array}{l}\text { water + ethyl butyrate } \\
\text { ethyl butyrate+methanol } \\
\text { water + ethyl butyrate } \\
\text { ethyl butyrate + methanol } \\
\text { water + ethyl butyrate } \\
\text { ethyl butyrate + methanol }\end{array}$ & $\begin{array}{l}\mathrm{VE} / \mathrm{cm}^{3} \cdot \mathrm{mol}^{-1} \\
\Delta \eta / \mathrm{mPa} \cdot \mathrm{s} \\
\sigma^{\mathrm{E}} \mathrm{b} / \mathrm{mN} \cdot \mathrm{m}^{-1}\end{array}$ & $\begin{array}{l}1.003 \\
-0.159 \\
4.718 \\
-0.055 \\
-46.805 \\
1.195\end{array}$ & $\begin{array}{l}-0.069 \\
5.524 \\
-0.028 \\
\\
0.613\end{array}$ & $\begin{array}{l}0.023 \\
1.000\end{array}$ & $\begin{array}{l}0.026 \\
0.004 \\
0.003 \\
0.001 \\
0.030 \\
0.020\end{array}$ \\
\hline
\end{tabular}

a The values of the standard deviation, $\mathrm{S}$, and the parameters are expressed in the units of the related property. ${ }^{\mathrm{b}}$ The coefficients $\mathrm{A}_{0}$, $A_{1}$, and $A_{2}$ correspond to $A, B$, and $C$, respectively, in eq 6.

Table 7. Fitted Coefficients of Eq 7 to the Excess Molar Volume, VE, and to the Viscosity Deviation, $\Delta \eta$, and of Eq 9 to the Excess Surface Tension, $\sigma^{\mathrm{E}}$, for the System Water (1) + Ethyl Butyrate (2) + Methanol (3) ${ }^{a}$

\begin{tabular}{|c|c|c|c|c|c|}
\hline property & $A_{1}$ & $\mathrm{~B}_{1}$ & $\mathrm{~B}_{2}$ & & $S$ \\
\hline $\begin{array}{l}\mathrm{VE} / \mathrm{cm}^{3} \cdot \mathrm{mol}^{-1} \\
\Delta \eta / \mathrm{mPa} \cdot \mathrm{s}\end{array}$ & $\begin{array}{l}-5.688 \\
-13.393\end{array}$ & $\begin{array}{l}-2.769 \\
-13.552\end{array}$ & $\begin{array}{l}-5.998 \\
-10.579\end{array}$ & & $\begin{array}{l}0.026 \\
0.011\end{array}$ \\
\hline property & $D_{1}$ & $D_{2}$ & $D_{3}$ & $\mathrm{D}_{4}$ & $\mathrm{~S}$ \\
\hline$\sigma^{\mathrm{E}} / \mathrm{mN} \cdot \mathrm{m}^{-1}$ & -53.695 & -196.907 & 92.456 & -1.466 & 0.17 \\
\hline
\end{tabular}

a The values of the standard deviation, $\mathrm{S}$, and the parameters are expressed in the units of the related property.

Table 8. Coefficients of Eq 10 Fitted to the Liquid Interfacial Tension, $\sigma^{\prime}$, for the System Water (1) + Ethyl Butyrate (2) + Methanol (3)

\begin{tabular}{ccccc}
\hline & & \multicolumn{2}{c}{$\mathrm{k}$} & \\
\cline { 3 - 4 } $\mathrm{X}_{0}{ }^{\mathrm{a}}$ & $\sigma_{0}^{\prime} / \mathrm{mN} \cdot \mathrm{m}^{-1}$ & $\mathrm{k}_{1}$ & $\mathrm{k}_{2}$ & $\mathrm{~S} / \mathrm{mN} \cdot \mathrm{m}^{-1}$ \\
\hline 2.688 & 15.3 & 1.156 & 0 & 0.29 \\
& & 1.355 & -0.157 & 0.02
\end{tabular}

a $X_{0}$ is defined by eq 11 when $x_{3}=0$.

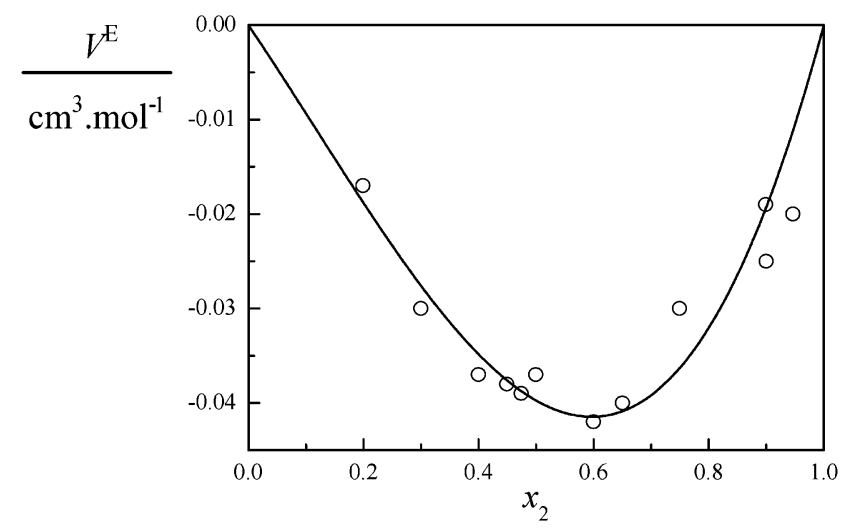

Figure 1. Excess molar volumes, $\mathrm{VE}$, of ethyl butyrate (2) + methanol (3) as a function of mole fraction of the ester, $x_{2}$, at 303.15 $\mathrm{K}$ and atmospheric pressure. The curve represents eq 5.

is the interfacial tension of the partially miscible binary pair, which corresponds to $x_{3}=0$ and $X=X_{0}$ in eq 11 . $x_{1}^{\alpha}$ is the mole fraction of component 1 in the liquid phase $\alpha$, which is richer in component $2, x_{2}^{\beta}$ is the mole fraction of component 2 in the phase richer in component 1 , and $x_{3 p}$ is the mole fraction of component 3 in the phase poor in it. $\mathrm{Li}$ and $\mathrm{Fu}$ considered the parameter $\mathrm{k}$ as an adjustable one in eq 10, and they have also used a more general form, $\mathrm{k}$ $=\mathrm{k}_{1}+\mathrm{k}_{2} \mathrm{X}$.

The optimized coefficients, $A_{k}$ (eq 5), A, B, and C (eq 6), and the standard deviations, $\mathrm{S}$, obtained from the Levenberg-Marquardt method of fitting, are given in Table 6 . The coefficients $A_{1}$ and $B_{i}$ of eq $7, D_{i}$ of eq 9 , and the standard deviations of the corresponding fittings are given in Table 7. The parameter $k$ has been calculated consider-

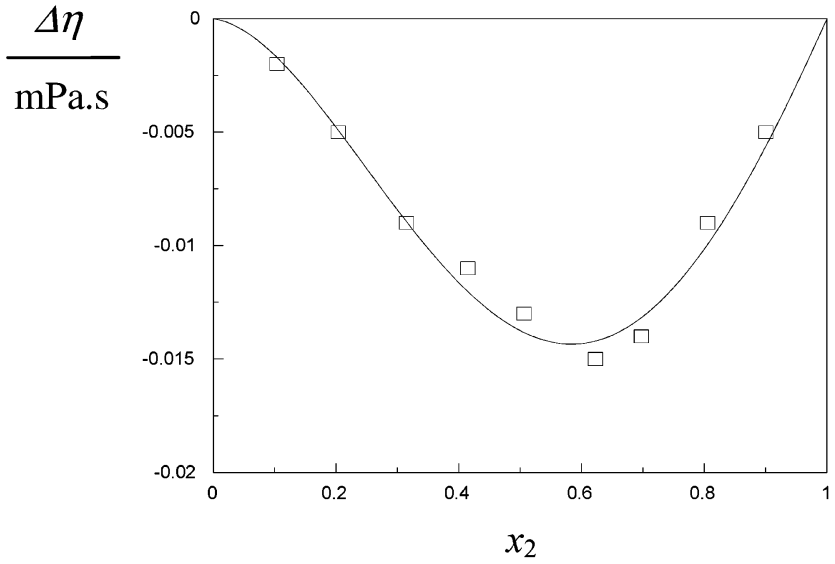

Figure 2. Viscosity departures, $\Delta \eta$, of ethyl butyrate (2) + methanol (3) as a function of mole fraction of the ester, $x_{2}$, at 303.15 $\mathrm{K}$ and atmospheric pressure. The curve represents eq 5 .

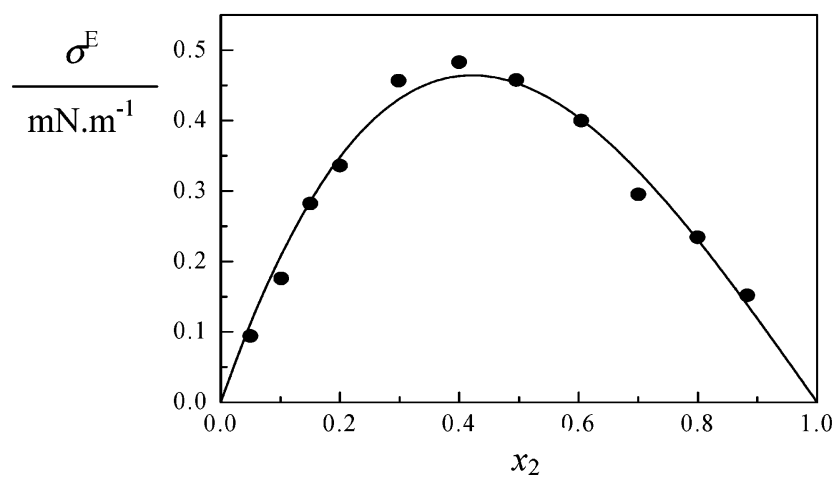

Figure 3. Excess surface tension, $\sigma^{\mathrm{E}}$, of ethyl butyrate (2) + methanol (3) as a function of mole fraction of the ester, $x_{2}$, at 303.15 $\mathrm{K}$ and atmospheric pressure. The curve represents eq 6 .

ing that $k=k_{1}$ and that $k=k_{1}+k_{2} X$. The results of the fittings are listed in Table 8.

The standard deviation of the fittings, $\mathrm{S}$, is defined as

$$
\mathrm{S}=\left[\sum\left(\mathrm{Z}_{\text {exp }}-\mathrm{Z}_{\text {calc }}\right)^{2} /(\mathrm{M}-\mathrm{n})\right]^{1 / 2}
$$

where $\mathrm{Z}$ represents $\mathrm{VE}, \Delta \eta, \sigma^{\mathrm{E}}$, or $\sigma^{\prime}$ and $\mathrm{M}$ and $\mathrm{n}$ represent the numbers of the experimental points and parameters, respectively.

The experimental determinations of surface tension for the ternary system were made following lines of constant ratio $\mathrm{z}\left(=\mathrm{x}_{1} / \mathrm{x}_{3}\right)$. In Figure 4 we have represented experimental $\sigma^{\mathrm{E}}$ values and fitted lines of constant $\left(\mathrm{x}_{1} / \mathrm{x}_{3}\right)$ obtained using eq 8.

\section{Conclusions}

The densities, viscosities, and surface and interfacial tensions of the system water + ethyl butyrate + methanol 


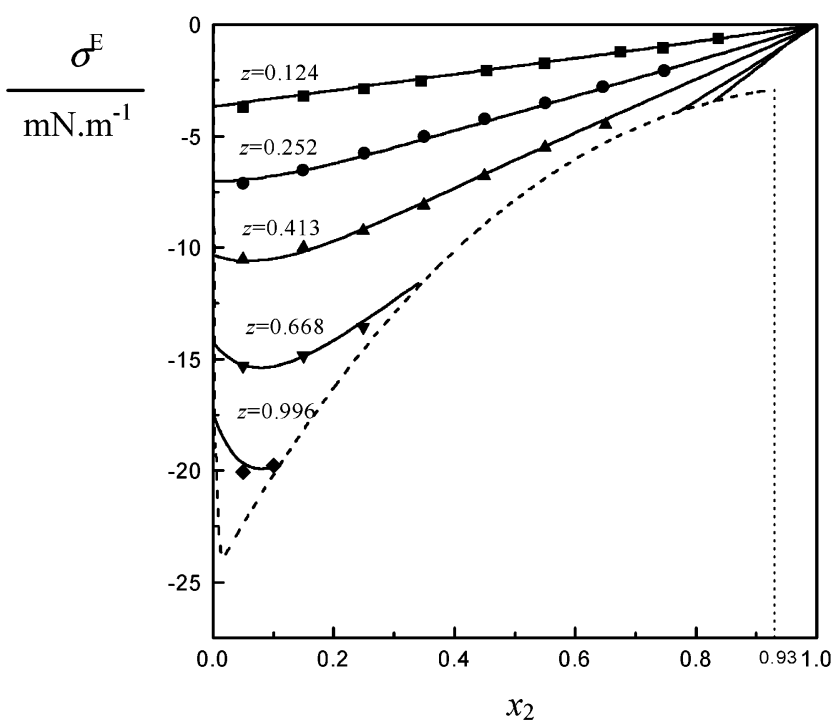

Figure 4. Excess surface tension, $\sigma^{\mathrm{E}}$, for the ternary system water (1) + ethyl butyrate (2) + methanol (3), at $303.15 \mathrm{~K}$ and atmospheric pressure, along the curves of constant ratio $z=x_{1} / x_{3}$ as a function of the ester composition, $x_{2}$. Symbols represent the experimental points. Solid curves were calculated with eq 8 . The dashed line is the binodal curve. ${ }^{5}$

have been determined experimentally at $303.15 \mathrm{~K}$ and atmospheric pressure.

Binary as well as ternary $\mathrm{V}^{\mathrm{E}}$ and $\Delta \eta$ data were correlated using only up to three parameters in the Redlich-Kister polynomials. For the binary surface tensions, correlation of the experimental data was made using a three parameter equation (eq 6), whereas, for theternary system, a ternary term, $\sigma_{\mathrm{T}}^{\mathrm{E}}$ (eq 9), with four adjustable constants was used.

The simple equation of $\mathrm{Li}$ and $\mathrm{Fu}$ correlates well the liquid ternary interfacial tension data, with a standard deviation of the fitting $<0.3 \mathrm{mN} \cdot \mathrm{m}^{-1}$.

\section{Literature Cited}

(1) Natividade, N. A. T.; Ferreira, A. G. M.; Fonseca, I. M. A. Densities and Excess Molar Volumes of Water+Propyl Acetate+Propan-1-ol and Its Constituent Binaries at 303.15 K. J . Chem. Eng. Data 1997, 42, 1232-1234.
(2) Visak, Z. P.; Ferreira, A. G. M.; Fonseca, I. M. A. Densities and Viscosities of the Ternary Mixtures Water+Butyl Acetate+M ethanol and Water+Ethyl Propionate+Methanol at $303.15 \mathrm{~K}$. J. Chem. Eng. Data 2000, 45, 926-931.

(3) Giro, F.; Goncalves, M. F.; Ferreira, A. G. M.; Fonseca, I. M. A Viscosity and Density Data of the System Water+n-Pentyl Acetate+Methanol. Calculations with a Redlich-K wong-Soave Equation of State. Fluid Phase Equilib. 2002, 51, 1-16.

(4) Santos, B. M. S. Ferreira, A. G. M. Fonseca, I. M. A. Surface and Interfacial Tensions of the Systems Water+n-Butyl Acetate+ Methanol and Water+n-Pentyl Acetate+Methanol at $303.15 \mathrm{~K}$. Fluid Phase Equilib. 2003, 208, 1-21.

(5) Rao, R. J .; Rao, C. V. Ternary Liquid Equilibria: MethanolWater-Esters. J. Appl. Chem. 1957, 7, 435-439.

(6) J asper, J . J . The Surface Tension of Pure Liquid Compounds. J . Phys. Chem. Ref. Data 1972, 1, 841-1009.

(7) Li, B.; Fu, J . Interfacial Tensions of Two-Liquid-Phase Ternary Systems. J . Chem. Eng. Data 1992, 37, 172-174.

(8) Dizechi, M.; Marschall, E. Viscosity of Some Binary and Ternary Liquid Mixtures. J . Chem. Eng. Data 1982, 27, 358-363.

(9) Rao, R. J .; Rao, C. V. Ternary Liquid Equilibria Systems: N-Propanol-Water-Esters. J . Appl. Chem. 1959, 9, 69-73.

(10) Oswald, S. R.; Oswald, P.; Dave, J. P. VE of Mixtures Containing Alkyl Acetate, or Ethyl Alkanoate, or Ethyl Bromoalkanoate with n-Hexane. Fluid Phase Equilib. 1994, 98, 225-234.

(11) Wilhoit, R. C.; Zwolinski, B. J . Physical and Thermodynamic Properties of Aliphatic Alcohols. J . Phys. Chem. Ref. Data 1973 2, Suppl. 1.

(12) Pikkarainen, L. Densities and Viscosities of Binary Mixtures of N,N-Dimethylacetamide with Aliphatic Alcohols. J. Chem. Eng. Data 1983, 28, 344-347.

(13) Kestin, J .; Sokolov, M.; Wakeham, W. A. Viscosity of Liquid Water in the Range $-8{ }^{\circ} \mathrm{C}$ to $150{ }^{\circ} \mathrm{C}$. J. Phys. Chem. Ref. Data 1978, 7 , 941-948.

(14) Reid, R. C.; Prausnitz, J . M.; Poling, B. E. The Properties of Gases and Liquids, 4th ed.; McGraw-Hill: New York, 1987.

(15) Aralaguppi, M. I.; J adar, C. V.; Aminabhavi, T. M. Density, Viscosity, Refractive Index, and Speed of Sound in Binary Mixtures of Acrylonitrile with Methanol, Ethanol, Propan-1-ol, Butan-1-ol, Pentan-1-ol, Hexan-1-ol, Heptan-1-ol, and Butan-2ol. J. Chem. Eng. Data 1999, 44, 216-221.

(16) Aminabhavi, T. M.: Patil, V. B. Density, Viscosity, and Speed of Sound in Binary Mixtures of 1-Chloronaphthalene with Methanol Ethanol, Propan-1-ol, Butan-1-ol, Pentan-1-ol, and Hexan-1-ol in the Temperature Range (298.15-308.15) K. J . Chem. Eng. Data 1998, 43, 504-508.

(17) Lide, D. R. Handbook of Chemistry and Physics, 76th ed.; CRC Press: New York, 1995

(18) Redlich, O.; Kister, A. Algebraic Representation of Thermodynamic Properties and the Classification of Solutions. Ind. Eng Chem. 1948, 40, 345-348.

Received for review March 19, 2003. Accepted J une 19, 2003.

J E0301500 